\title{
Influence of Environment Corrosion on the Fatigue Performance of Expressway Bridges
}

\author{
Xin Qin ${ }^{1,2, *}$, Dou Yuanming ${ }^{1,2}$, Ma Najing ${ }^{1,2}$ and Xin Yanan ${ }^{3}$ \\ ${ }^{1}$ School of Civil Engineering, Hebei University of Technology, Tianjin 300401, China \\ ${ }^{2}$ Civil Engineering Technology Research Center of Hebei Province, Tianjin 300401, China \\ ${ }^{3}$ Department of Geography, The Pennsylvania State University, University Park, PA 16802, United States
}

Received 19 November 2016; Accepted 18 January 2017

\begin{abstract}
In-service bridges along rivers or seas are constantly exposed to harsh environmental conditions, which contain corrosive substances that seriously affect the structural safety of these bridges. In its service processes, cyclic stress accelerates this corrosive effect, which aggravates fatigue and results in the failure of the materials utilized. Consequently, the expected endurance life is not reached. In this study, six test beams were designed, produced, and subsequently subjected to a chloride salt corrosion test to explore the effects of environment corrosion on the fatigue performance of bridge structures and reveal the development process of fatigue failure and its influencing factors. Fatigue amplitude was determined through comprehensive static and expressway vehicle load tests. Fatigue tests were also conducted on corrosion test beams, and the material properties of the pre-stressed concrete bridge after corrosion were analyzed under the effect of long-term traffic load. Fatigue brittle failure occurred in the form of reinforcement fracture in all test beams after corrosion. The service life of test beams with corrosion rates of $5 \%$ and $10 \%$ decreased by $53 \%$ and $96 \%$, respectively, compared with that of a non-corroded beam at a fixed load level. Residual strain of the test beam with a corrosion rate of $10 \%$ under failure was twice that of the test beam with a corrosion rate of $5 \%$. The maximum and residual strain curves of all test beams presented "three-phased" characteristics. After corrosion, the residual concrete strain in the compression zone and the frequency of the fatigue tests exhibited a double-logarithmic linear relation. Strain variation in the prestressed reinforcement after corrosion was significant, but the strain variation in the ordinary reinforcement was minimal. The analysis process and method of this study are also applicable to concrete members in other corrosive environments. The findings can provide a theoretical reference for fatigue performance analyses under different corrosion conditions.
\end{abstract}

Keywords: Environment corrosion; Reinforcement corrosion; Pre-stressed concrete beam; Fatigue performance

\section{Introduction}

Expressways have become the lifeblood of economic development in various regions in China [1]. Compared with ordinary reinforced concrete structures, pre-stressed concrete structures can be extensively applied to the design and construction of expressway bridges and have become one of the main forms of long-span bridges in China; they can maximize material properties, improve crack resistance and stiffness, and increase the structural span of structures or members [2],[3]. The dead weight and dead load of prestressed concrete members are reduced with the application of high-strength concrete and high-strength reinforcement. Consequently, the proportion occupied by fatigue load increases. The common application of the design theory of ultimate state places many members in a high-stress state; consequently, fatigue life is significantly affected, and fatigue failure is aggravated [4],[5]. Therefore, research on the mechanism and properties of pre-stressed concrete beams under the effect of the fatigue load is crucial.

Most test analyses based on the fatigue failure mechanism focused on reinforced concrete beams in a non-

- E-mail address: xinxin19870521@126.com

ISSN: 1791-2377 @ 2017 Eastern Macedonia and Thrace Institute of Technology. All rights reserved. corrosive environment [6],[7]. However, the environment where bridges actually operate is complicated, and corrosion fatigue frequently occurs [8-10]. Corrosion fatigue results in the degradation of structural members in a corrosive environment after bearing the effect of cyclic load [11]. Degradation of reinforced concrete members in a corrosive environment is mainly manifested by the cracking of the members due to corroded concrete. As a result, the reinforcement becomes corroded. Corrosion aggravates the defects on the reinforcement surface and forms fatigue crack sources, and a corrosive layer on the reinforcement surface damages the bond between the reinforcement and concrete [12]. Even when corrosion is not serious, under the effect of cyclic load, structural members rapidly undergo failure, and corrosion pits form due to active fatigue cracking. Therefore, environment corrosion aggravates the accumulation of fatigue damages in the structure and reduces the structural stiffness of bridges. It affects the normal use of bridges and their structural safety. Moreover, due to the relatively low prioritization of environment corrosion in early-stage bridge structural design and the increasing number of in-service bridges in recent years, the service duration of bridge structures cannot be extended, and the safety and reliability of existing bridges cannot be guaranteed due to the uncertainty of the corrosion degree of corroded parts caused 
by the complicated corrosive environment [13],[14]. Therefore, a fatigue test must be urgently implemented on structural members under environment corrosion to adjust the structural design of pre-stressed concrete beams to the actual service environment.

With the preceding analysis as a basis, this study selected a $16 \mathrm{~m}$ standard-span pre-stressed concrete beam in a reconstruction and extension project of an expressway as the research object. Similarity theory and damage mechanics were utilized as theoretical bases. A reduced-scale test beam was designed and exposed to corrosion. Fatigue performance tests were conducted on pre-stressed concrete under constant amplitude fatigue load and different corrosion rates.

\section{State of the art}

Reinforced concrete members in active service for many years suffer corrosion of different degrees due to environmental effects, including air. The main damage caused by member corrosion is reinforcement corrosion. The mechanical properties of the members change, and the sectional area decreases after reinforcement corrosion. Both changes result in the degradation of the fatigue-bearing capacity of the member. Theoretical and practical researchers both local and international have conducted numerous studies on the influence of reinforcement corrosion on the static performance of concrete structures. Wang et al studied the effects of reinforcement corrosion on the flexural capacity of concrete beams by conducting a static load test on a corroded reinforced concrete (RC) beam. The results indicated that the main beam reinforcement is the key factor that causes the degradation of bearing capacity. The maximum crack width of concrete cracking is proportionally related to the internal reinforcement corrosion rate. However, the study merely indicated that bearing capacity and crack development are influenced and did not expound on the action mechanism of reinforcement corrosion [15]. Cabrera et al used the rapid electrochemical corrosion method to control the reinforcement corrosion volume according to Faraday's law and determined the relationship between structural bearing capacity degradation and corrosion rate by measuring variations in the bonding strength, crack width, and deflection of beam members. The electrochemical corrosion method can be used for real-time measurement of the instantaneous corrosion rate with linear polarization technology and high measurement speed; it can also shorten the test cycle by a large margin compared with natural corrosion [16]. As can be seen, previous scholars mainly studied the single effect of reinforcement corrosion on the static performance of beams in the early phase of research. They conducted detailed research on the failure mode, bearing capacity, and deformation of the members. However, the reinforcement corrosion process in practical projects always occurs when a member bears a reciprocal load. The load effect can result in accelerated degradation caused by corrosion.

Malumbela pointed out that if a correlation exists between the load effect and structural corrosion, research conclusions that do not consider the load effect may not truthfully reflect the stress characteristics of in-service structures. Yoon et al. conducted tests on the interaction between load and reinforcement corrosion and a reinforcement deformation test under different continuous load levels (i.e., $0.45 \%$ and $75 \%$ of the ultimate load) of a $100 \mathrm{~mm} \times 150 \mathrm{~mm} \times 1170 \mathrm{~mm} \mathrm{RC}$ beam; the deflection and bearing capacity variations of the beam under the interaction were obtained [17]. Although Yoon measured the deflection change, the relevant factors that can characterize structural properties (e.g., beam strain) were not discussed. Ballim et al. studied the effects of reinforcement corrosion and the cracking of the concrete cover on bond stress; after performing a rapid corrosion test, they found that the corrosion degree increases when the applied load level increases [18]. However, the researchers did not measure other parameters of structural behavior, so their results were limited. EI Maaddawy et al. reported that the load effect can significantly affect reinforcement corrosion in the early phase, but the influence in the end phase is unobvious. Monitoring of corrosion current density and corrosion crack development has shown that existing reinforcement corrosion models might overestimate the service life of structures [19]. However, the theoretical basis for selecting the corrosion center as the monitoring point of maximum crack is unexplained and needs to be studied. Generally, many scholars have studied the interaction between load and reinforcement corrosion. The effects of load level on the deformation performance and bearing capacity of $\mathrm{RC}$ beams exerted through different corrosion acceleration means under different load levels have also been studied. However, these studies focused on RC beams, and only a few used pre-stressed concrete members.

The aforementioned research methods and conclusions related to flexural members of ordinary RC are noteworthy references; however, the degradation of the flexural performance of pre-stressed concrete members is different from that of ordinary RC members because of the high-stress working status of pre-stressed concrete members and their high sensitivity to corrosive effects [20],[21]. Zhu used the static load test method to test the midspan deflection and sectional concrete stress of a beam. The researcher also conducted a finite element analysis of corroded and prestressed concrete beams. Emphasis was placed on finite element analysis of the overall structure of an entity bridge and verification of the static load test with the finite element method. Although several studies investigated the influence of the performance degradation law of entity bridges caused by corrosion, obtaining the direct relationship between corrosion and fatigue performance degradation of prestressed concrete bridges under reciprocal actions of vehicles during the service process remains difficult [22]. Therefore, in the present study, a fatigue test was conducted on a reduced-scale model beam to determine the fatigue performance of a real pre-stressed concrete beam. This test was based on research on the static properties of reinforcement corrosion and fully considered the coupling effect between environment corrosion and load.

The rest of this study is arranged as follows. A reasonable reduced-scale model is presented in Section 3. Bearing capacity and fatigue life are obtained through corrosion and equi-amplitude fatigue tests conducted through a manual simulation of the natural environment. A fatigue performance analysis from the aspects of material stress, strain, displacement, and deflection under different corrosion rates is presented in Section 4. The last section summarizes the entire research and provides relevant conclusions.

\section{Methodology}

\subsection{Model beam design}

A part of a pre-stressed hollow slab beam from an expressway bridge was utilized as a prototype to establish a 
reduced-scale model. The actual sectional dimensions of the hollow slab beam are shown in Fig. 1.

The reduced scale of the test model beam was 1:5, and the test beam was prepared with the pre-tensioning method. The model beam was a solid rectangular section ( $b \times h=180 \mathrm{~mm} \times 140 \mathrm{~mm}$ ), and the calculated span was $2.9 \mathrm{~m}$. The concrete material was similar to that of the prototype. The concrete strength grade was $\mathrm{C} 40$, the cover thickness was $25 \mathrm{~mm}$, and the diameter of the aggregate used by the concrete was not greater than $20 \mathrm{~mm}$. The $\Phi 7$ pre-stressed reinforcement was a pre-stressed wire. The tensile stress was 0.73 times that of the standard tensile strength value, and the maximum tension value did not exceed 1.05 times. The ordinary reinforcement was HPB300 reinforcement with a diameter of $6 \mathrm{~mm}$. The stirrups were 12\# iron wires with a diameter of $2.6 \mathrm{~mm}$ interspaced at $100 \mathrm{~mm}$; the interspacing was narrowed to $50 \mathrm{~mm}$ near the support. The measured values of material strength are listed in Tables 1 and 2, and the arrangement of the reinforcement of the model beam section is shown in Fig. 2.

Table 1. Concrete compressive strength measured values

\begin{tabular}{c|c|c|c|c}
\hline Block types & Size $(\mathrm{mm})$ & Number & $\begin{array}{c}\text { Cube crushing strength } \\
(\mathrm{MPa})\end{array}$ & $\begin{array}{c}\text { Axial compressive strength } \\
(\mathrm{MPa})\end{array}$ \\
\hline Test cube & $150 \mathrm{~mm} \times 150 \mathrm{~mm} \times 150 \mathrm{~mm}$ & 3 & 41.6 & - \\
Prism block & $150 \mathrm{~mm} \times 150 \mathrm{~mm} \times 150 \mathrm{~mm}$ & 3 & - & 29.8 \\
\hline
\end{tabular}

Table 2. Strength steel measured values

\begin{tabular}{c|c|c|c|c}
\hline Steel types & Diameter $(\mathrm{mm})$ & Yield strength $(\mathrm{MPa})$ & Ultimate strength $(\mathrm{MPa})$ & Elongation $(\%)$ \\
\hline Pre-stressed wire & 7 & 1410 & 1,603 \\
Regular reinforcement & 6 & 316 & 4.2 \\
\hline
\end{tabular}

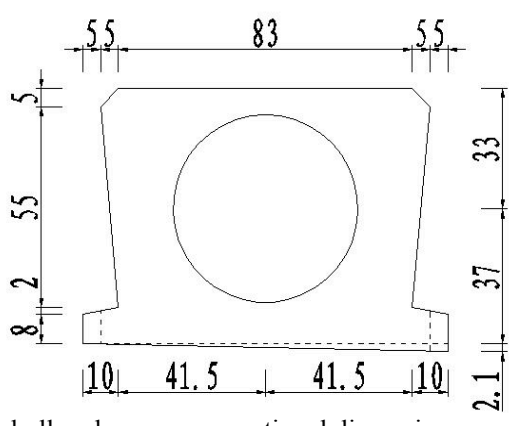

Fig. 1. $16 \mathrm{~m}$ hollow beam cross-sectional dimensions

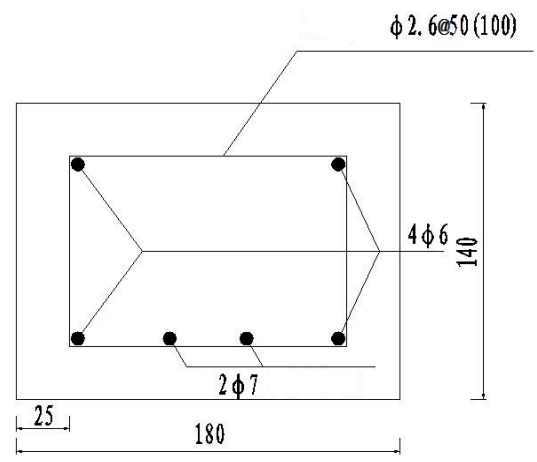

Fig. 2. Model beam section reinforcement figure

\subsection{Corrosion tests}

ny studies $[23,24]$ have been conducted on the vehicle load. A statistical analysis was conducted in the current study according to the expressway vehicle load $[25,26]$ to confirm the amplitude of fatigue load in this test. Considering the dead weight of the structure, bridge deck paving, vehicle running state, and laboratory conditions, the lower limit of the fatigue load was set to 0.15 times of the ultimate load. The upper limit of the fatigue load approximated the working load value (i.e., 0.6 ultimate load) according to the load effect and existing statistical load data. The ultimate load value was the result of the ultimate bearing capacity obtained through a static load test. For partially pre-stressed concrete structures, reinforcement stress suddenly increases when the concrete cracks. Therefore, the maximum and minimum load values selected in the fatigue test must make the reinforcement stress repeatedly span sudden increase points of its stress [27]. The details are shown in Table 3.

The accelerated corrosion method with discontinuous power switching was selected. Before switching the power on, the beam was half dipped in a $5 \%$ solution for $24 \mathrm{~h}$, and the stressed reinforcement wire was connected to the anode of a constant DC power source. A stainless steel plate in sodium chloride solution was connected to its cathode, and the solution was used for the reinforcement to gradually form a corrosion loop. The DC power source was kept constant during the process. Corrosion current was 1 $\mathrm{mA} / \mathrm{cm}^{2}$, and test beams of different corrosion rates were obtained by controlling two indexes (i.e., time and current density). Faraday's law states that the working current intensity and conduction time required for a test beam to reach a designed corrosion rate can be roughly calculated. The corrosion parameters are listed in Table 3. Fig. 3 shows the corrosion test, and Fig. 4 shows the DC power source utilized in the test.

Table 3. Load condition and electrochemical corrosion parameters

\begin{tabular}{|c|c|c|c|c|c|}
\hline Number & $\begin{array}{c}\text { Estimated corrosion } \\
\text { rate }(\%)\end{array}$ & $\begin{array}{l}\text { Loading } \\
\text { method }\end{array}$ & Loading instruction & $\begin{array}{c}\begin{array}{c}\text { Corrosion current } \\
(\mathrm{mA} / \mathrm{cm} 2)\end{array} \\
\end{array}$ & $\begin{array}{c}\text { Corrosion } \\
\text { time (h) }\end{array}$ \\
\hline PL1 & 0 & Static load & $\begin{array}{l}\text { Gradation loading, obtain the ultimate bearing } \\
\text { capacity }\end{array}$ & - & - \\
\hline PL2 & 5 & Static load & $\begin{array}{c}\text { Gradation loading, obtain the ultimate bearing } \\
\text { capacity }\end{array}$ & 1 & 37.50 \\
\hline PL3 & 10 & Static load & $\begin{array}{l}\text { Gradation loading, obtain the ultimate bearing } \\
\text { capacity }\end{array}$ & 1 & 74.98 \\
\hline PL4 & 0 & Fatigue & $P_{\min }=0.15 P_{u 0}, P_{\max }=0.6 P_{u 0}$ & - & - \\
\hline PL5 & 5 & Fatigue & $P_{\min }=0.15 P_{u 1}, P_{\max }=0.6 P_{u 1}$ & 1 & 37.50 \\
\hline PL6 & 10 & Fatigue & $P_{\min }=0.15 P_{u 2}, P_{\max }=0.6 P_{u 2}$ & 1 & 74.98 \\
\hline
\end{tabular}




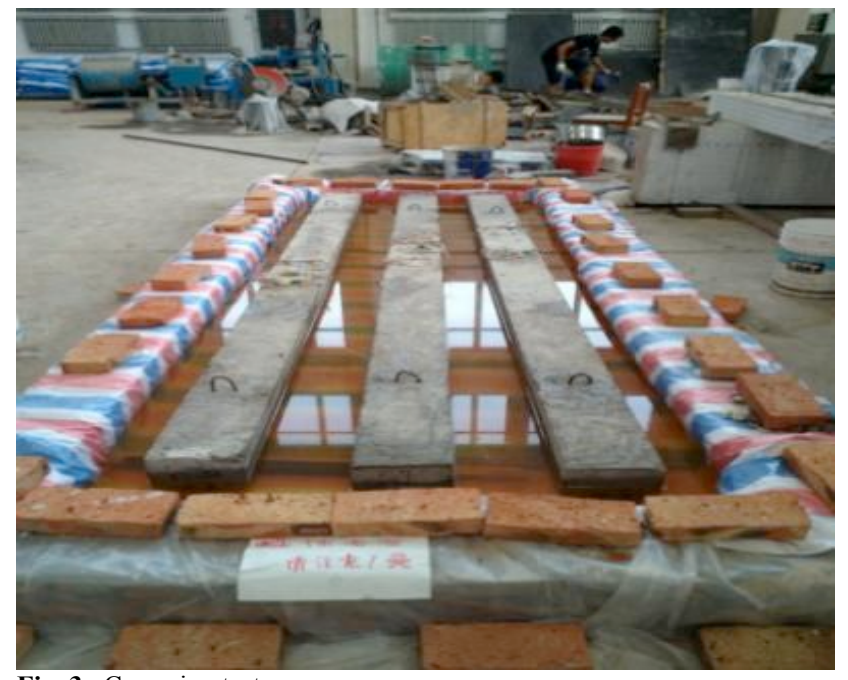

Fig. 3. Corrosion test

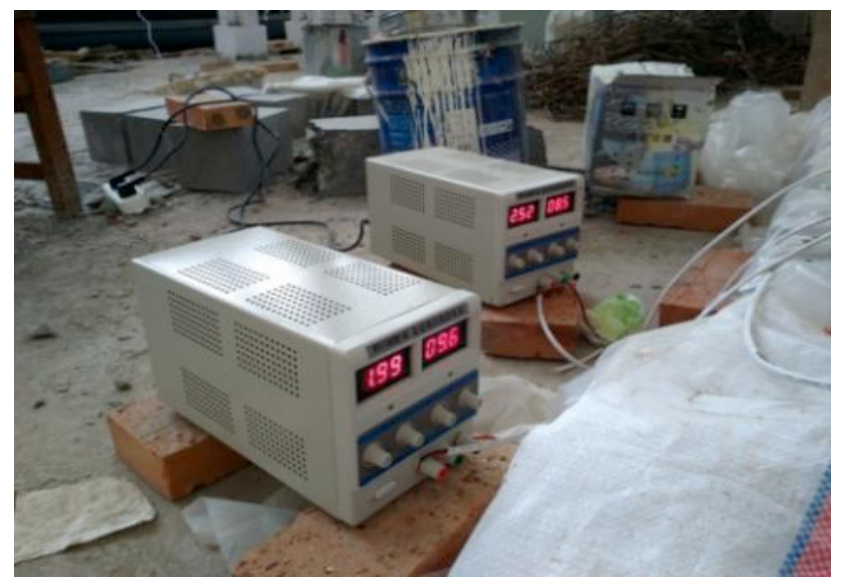

Fig. 4. DC electrical source of the corrosion test the test. Model test beams were produced under the same conditions, and trisection-point loading was completed in the static test with a hydraulic jack. The test results are listed in Table 4..

Three test beams with different corrosion rates were included in the test. An MTS electro-hydraulic servo fatigue testing machine with a loading frequency of $3.5 \mathrm{~Hz}$ was used The test is shown in Fig. 5. The upper and lower limit values of the applied load were obtained according to Table 4, and the test results are listed in Table 5.

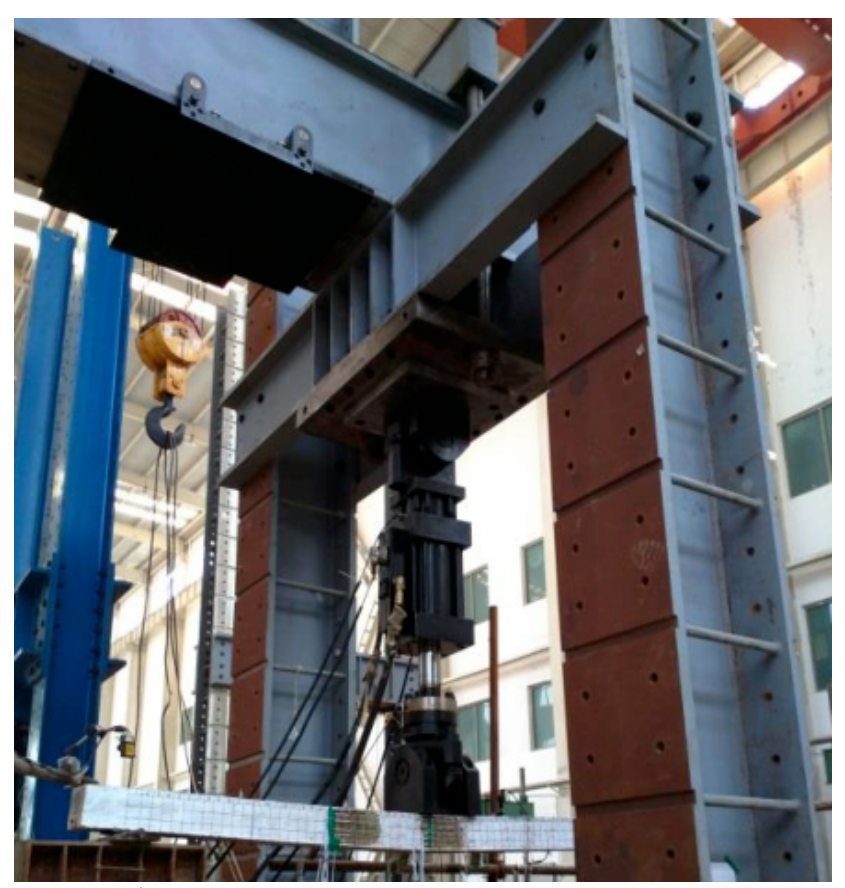

Fig. 5. Fatigue test

\subsection{Summary of test results}

Three static load test beams (one non-corroded and two corroded beams) with different corrosion rates were used in

Table 4. Results of model beams with different corrosion rates under static load

\begin{tabular}{c|c|c|c|c|c|c}
\hline Number & $\begin{array}{c}\text { Corrosion level of } \\
\text { steel rebar (\%) }\end{array}$ & $\begin{array}{c}\text { Actual corrosion } \\
\text { rate (\%) }\end{array}$ & $\begin{array}{c}\text { Cracking } \\
\text { load (kN) }\end{array}$ & $\begin{array}{c}\text { Ultimate bearing } \\
\text { capacity (kN) }\end{array}$ & Failure mode & Failure style \\
\hline PL1 & 0 & 0 & 8 & 25 & Bending failure & Ductility \\
PL2 & 5 & 4.25 & 10 & 28 & Bending failure & Ductility \\
PL3 & 10 & 8.90 & 6 & 23 & Bending failure & Ductility \\
\hline
\end{tabular}

Table 5. The results of model beams with different corrosion rate under fatigue load

\begin{tabular}{c|c|c|c|c|c|c|c}
\hline Number & $\begin{array}{c}\text { Estimated } \\
\text { corrosion } \\
\text { rate (\%) }\end{array}$ & $\begin{array}{c}\text { Actual } \\
\text { corrosion } \\
\text { rate (\%) }\end{array}$ & $\begin{array}{c}\text { Lower limit of } \\
\text { load (kN) }\end{array}$ & $\begin{array}{c}\text { Upper limit of load } \\
\mathbf{( k N )}\end{array}$ & $\begin{array}{c}\text { Fatigue life } \\
\text { (million) }\end{array}$ & $\begin{array}{c}\text { Static load } \\
\text { Failure types } \\
\text { limit load (kN) }\end{array}$ \\
\hline PL4 & 0 & 0 & 4 & 15 & 200 & Bending failure \\
PL5 & 5 & 4.87 & 4 & 17 & 92.92 & fatigue failure \\
PL6 & 10 & 11.21 & 4 & 14 & 6.47 & fatigue failure \\
\hline
\end{tabular}

\section{Result Analysis and Discussion}

\subsection{Beam failure mode under repeated fatigue load}

Test beams PL5 and PL6 suffered fatigue brittle failure in the form of reinforcement cracking (Fig. 6). Compared with the failure mode of non-corroded test beam PL4, the local part of the corroded test beams suffered bond failure caused by longitudinal cracks generated after the test beams suffered corrosion. The number of cracks that developed on beam PL4 was small, and the cracks were distributed sparsely. Many dense cracks were generated on corroded test beam PL5. The number of cracks on corroded test beam PL6 was second to that on PL5. PL6 also suffered brittle failure along the major crack without a clear sign. When the load level was fixed, the increase in the corrosion rate resulted in a sudden shortening of the fatigue life of the test beams. The fatigue life of the test beams with corrosion rates of 5\% and 
$10 \%$ decreased by $53.54 \%$ and $96.77 \%$, respectively, compared with that of the non-corroded test beam.

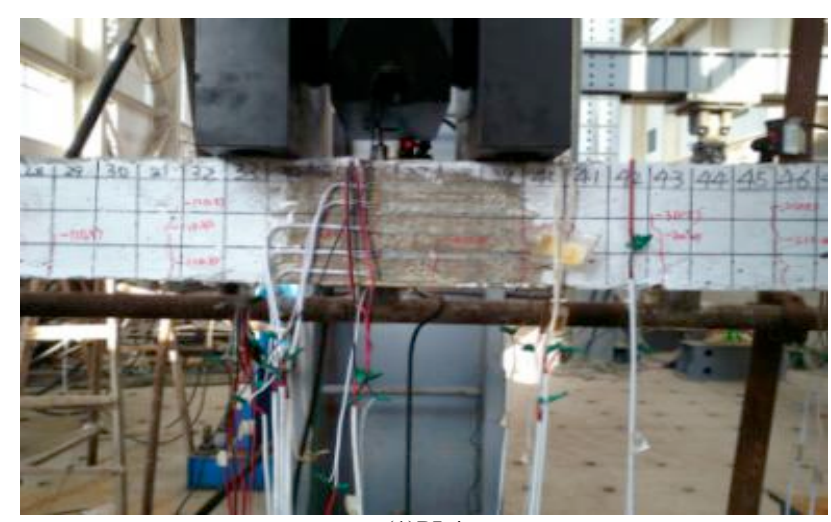

(1)PL4

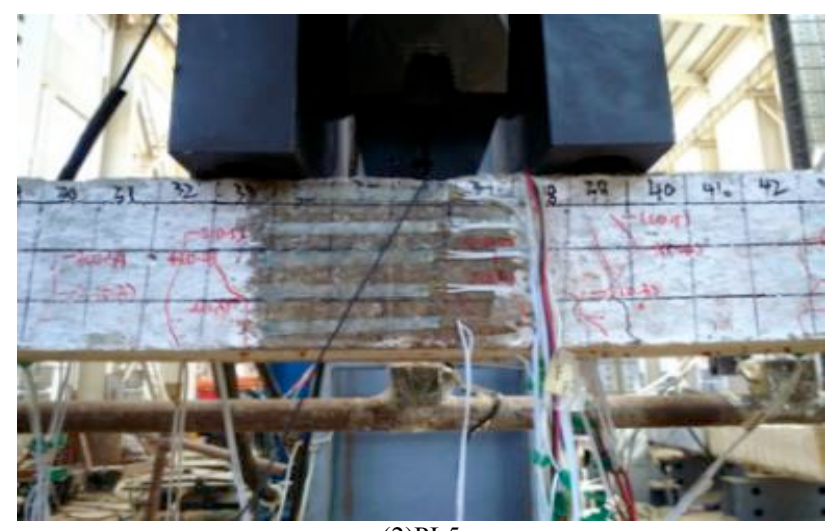

(2)PL5

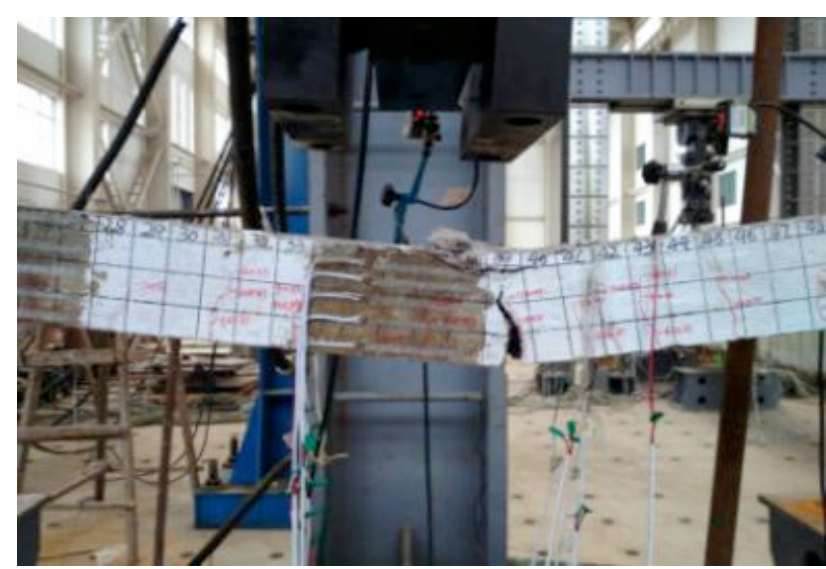

(3)PL6

Fig. 6. PL4 to PL6 failure patterns under fatigue load

\subsection{Load-displacement analysis of test beams under different corrosion rates}

The overall curve change in Fig. 7 shows that with the progressive increase in fatigue repetition times, the slope of the load-displacement curve of non-corroded test beam PL4 was basically unchanged. By contrast, those of corroded test beams PL5 and PL6 continuously decreased, and the higher the corrosion rate was, the more obvious the slope decreased. Beam displacement under unloading increased, unlike that of the beam under loading for each load stage. This scenario indicates that during the increase in the cycle index of the load, an equal cycle index of fatigue load increased the failure degrees of the beams. Plastic deformation also gradually occurred on the test beams.

As the cycle index of the fatigue load for beam PL4 increased, its plastic deformation was mainly generated from the initial test phase. The overall process basically presented a linear growth. Plastic deformation gradually increased with the progressive increase in the load repetition times, and plastic deformation was mainly generated from the initial test phase before beam failure. The increment in the plastic deformation of beam PL5 was much larger than that of PL4, which indicates that the test beam entered the yield phase in advance after reinforcement corrosion. This condition is due to factors, such as corrosion pits and corrosion-expansion cracks of the reinforcement. The slope of the loaddisplacement curve for test beam PL6 decreased, and the increase in plastic deformation mainly occurred before the failure of the test beam. All of these results prove that an increase in the corrosion rate can cause brittle rupture of prestressed concrete beams.

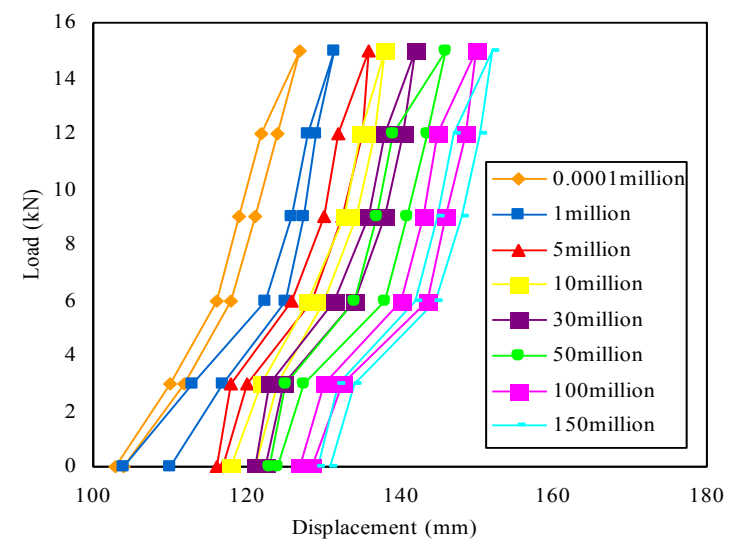

(1)PL4

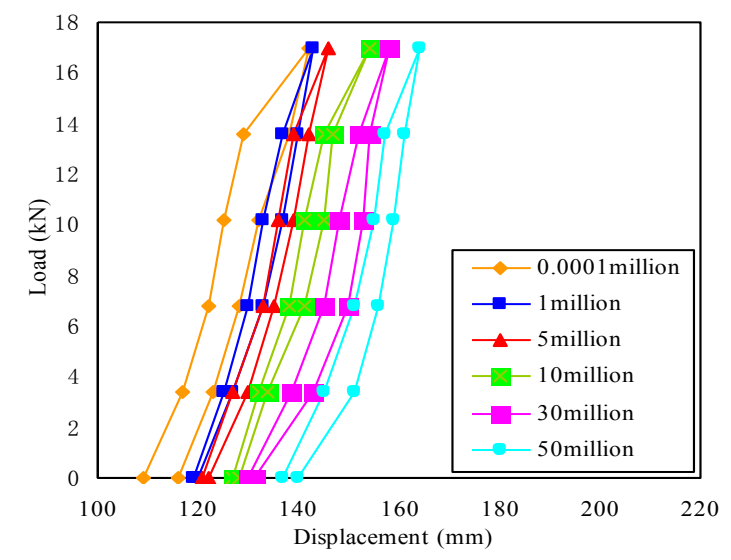

(2)PL5

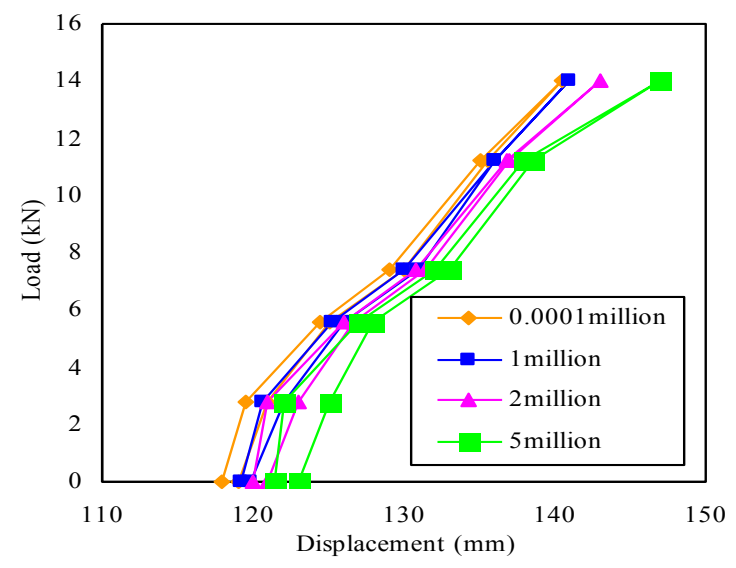

(3)PL6

Fig. 7. PL4 to PL6 failure patterns under fatigue load 


\subsection{Concrete strain analysis of test beams with different} corrosion rates

The maximum and residual strain curves of all the test beams presented "three-phase" characteristics, namely, slow, stable, and rapid growth phases of concrete strain. A comparison of test beams PL4 and PL5 showed that the maximum concrete strain of the lightly corroded test beam was slightly larger than that of the non-corroded test beam, but the residual strains of the two were basically identical. A comparison of test beams PL5 and PL6 showed that the maximum strain of concrete in the compressive zone suddenly increased with the progressive increase in the reinforcement corrosion rate. The residual concrete strain of beam PL6 after failure was approximately twice that of PL5 after fatigue failure.

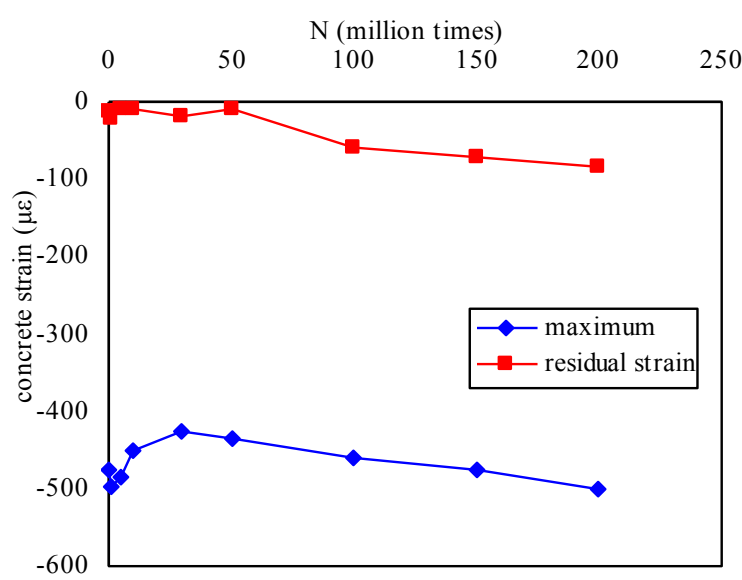

(1)PL4

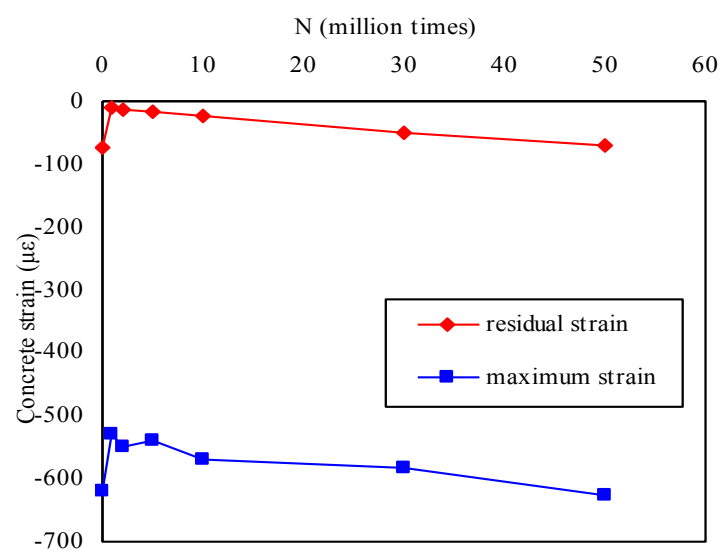

(2)PL5

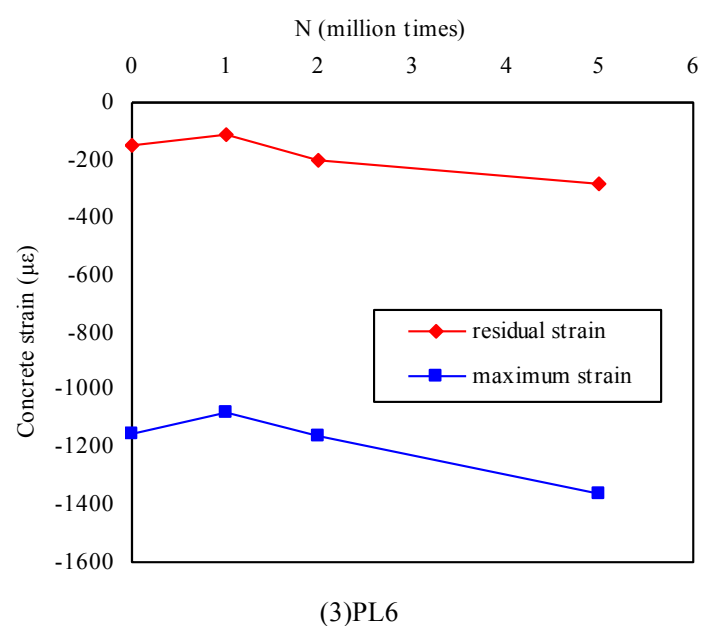

Fig. 8. Concrete strain-fatigue number curves of beams PL4 to PL6
Fig. 9 shows the linear fitting relations between the logarithms of residual strain and fatigue repetition times of the concrete of beams PL5 and PL6. The relations that exist in beams PL5 and PL6 are expressed by $\lg \varepsilon$ and $\lg N$, respectively. The figure shows that the linear relation between $\lg \varepsilon$ and $\lg N$ is evident, and the linear fitting equations are listed in Table 6.

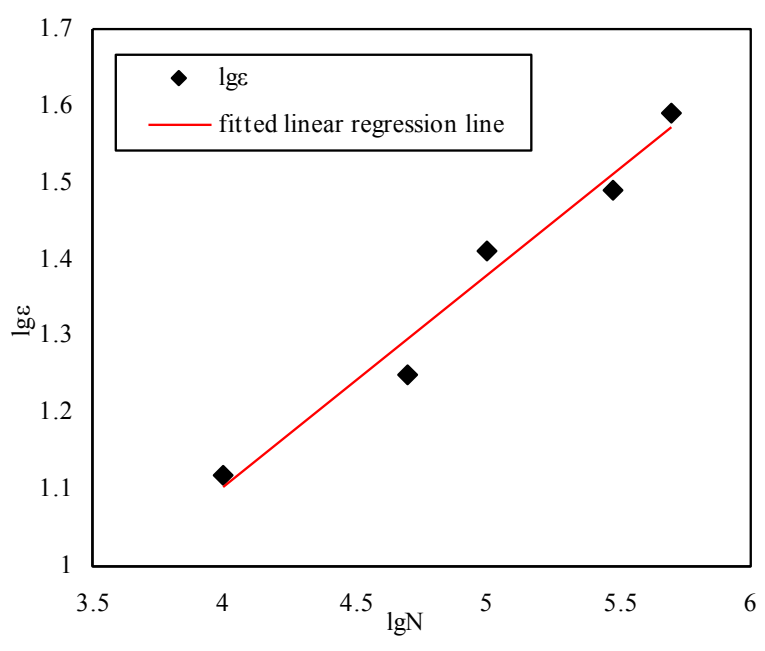

(1)PL5

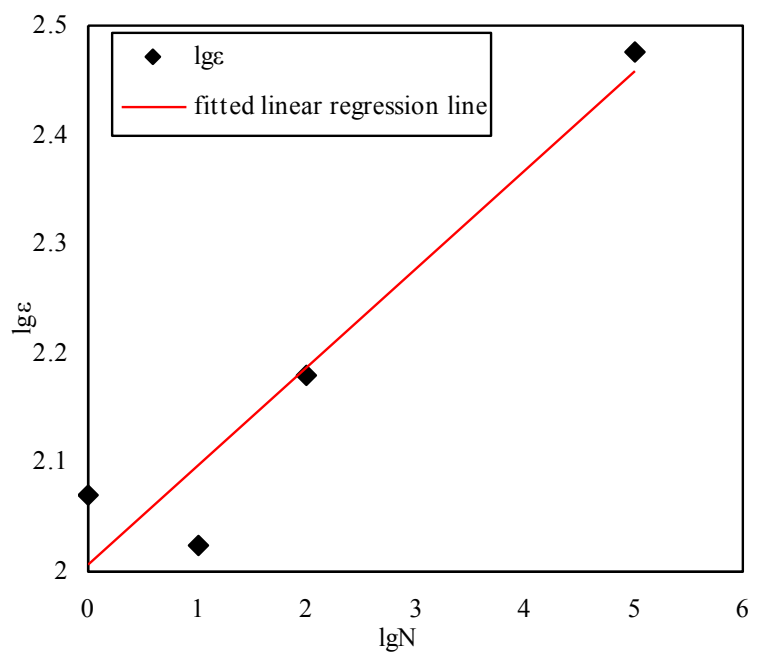

(2)PL6

Fig. 9. Linear fitting relationship between concrete residual strain and cycles of beams PL5 and PL6

Table 6. Unary linear regression equation of $\lg \varepsilon$ and $\lg \mathrm{N}$ for corrosive beams

\begin{tabular}{l|l|l|l}
\hline Number & $\begin{array}{l}\text { Unary linear regression } \\
\text { equation }\end{array}$ & $\begin{array}{l}\text { Linearly } \\
\text { dependent } \\
\text { coefficient }\end{array}$ & $\begin{array}{l}\text { Standard } \\
\text { deviation }\end{array}$ \\
\hline PL5 & $\lg \varepsilon=0.35686 \lg N-0.32272$ & 0.95454 & 0.04981 \\
PL6 & $\lg \varepsilon=0.0915 \lg N+2.00017$ & 0.96361 & 0.01782 \\
\hline
\end{tabular}

4.4 Fatigue strain analysis of reinforcements of test beams under different corrosion rates

Fig. 10 shows that the strain of ordinary reinforcement gradually increased with the progressive increase in the loading repetition times. The strain of the ordinary reinforcement of test beam PL4 presented a linear growth, and its curves remained parallel. The fatigue load stress was relatively low, and when the reinforcement was not corroded, 
the reinforcement of the test beam was basically in the elastic phase. Figs. 5.13 and 5.14 show that the strain change rules of the ordinary reinforcement of corroded test beams PL5 and PL6 can be roughly divided into three phases: elastic development, sudden increase, and stable development. The strain distributions of the ordinary reinforcement of test beams PL5 and PL6 were relatively dispersed and mainly presented linear growth in the initial loading phase (within 10,000 times). As the loading repetition times increased progressively, the strain of ordinary reinforcement abruptly increased, and the reinforcement underwent plastic deformation. Comparison shows that the stable development phase of test beam PL6 with a high corrosion rate before failure was not obvious, unlike that of test beam PL5 with a low corrosion rate.

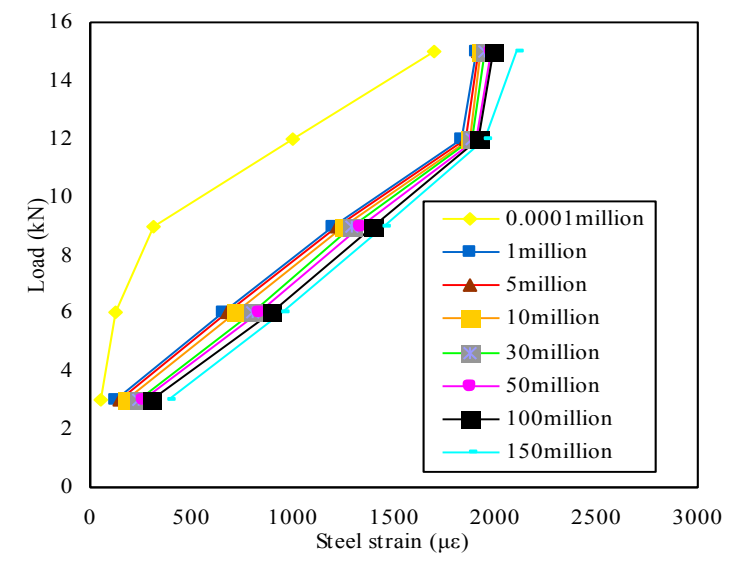

(1)PL4

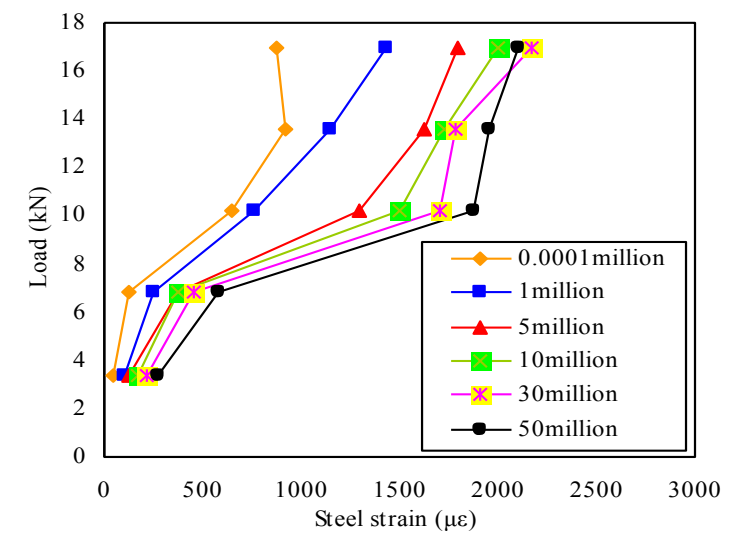

(2)PL5

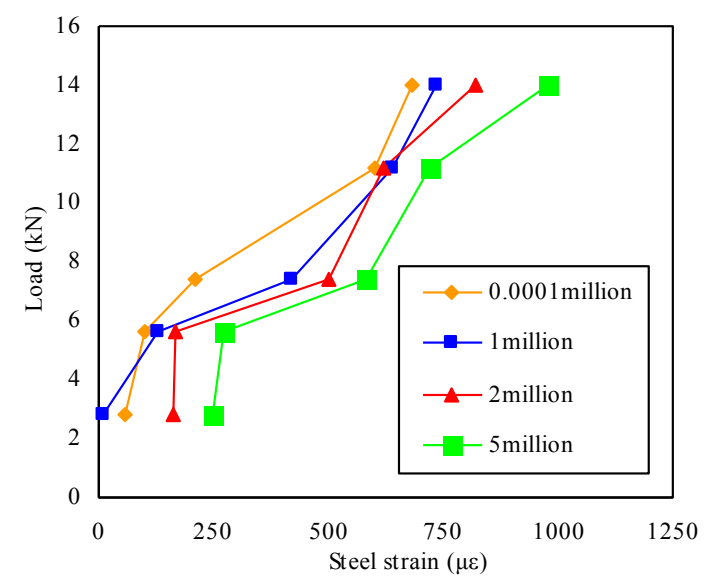

(3)PL6

Fig. 10. Reinforcement load-strain curve of beams PL4 to PL6
Fig. 11 shows that under the effect of cyclic load, the strain development trend of pre-stressed reinforcement was similar to that of ordinary reinforcement. The pre-stressed reinforcement strain correspondingly increased because of the progressive increase in the fatigue repetition times. Different from those of ordinary reinforcement, the prestressed reinforcement strains of beams PL4 to PL6 presented linear growth in the early loading phase. As the corrosion rate increased, the strain of the pre-stressed reinforcement after an equal cycle index of fatigue became larger than that of the beams under the fatigue test. For example, the pre-stressed strains of test beam PL6 after 50,000 times of fatigue repetition were about 2. 5 times that of test beam PL5. Strain of test beam PL6 under failure was about 1.1 and 1.8 times those of beams PL5 and PL4, respectively.

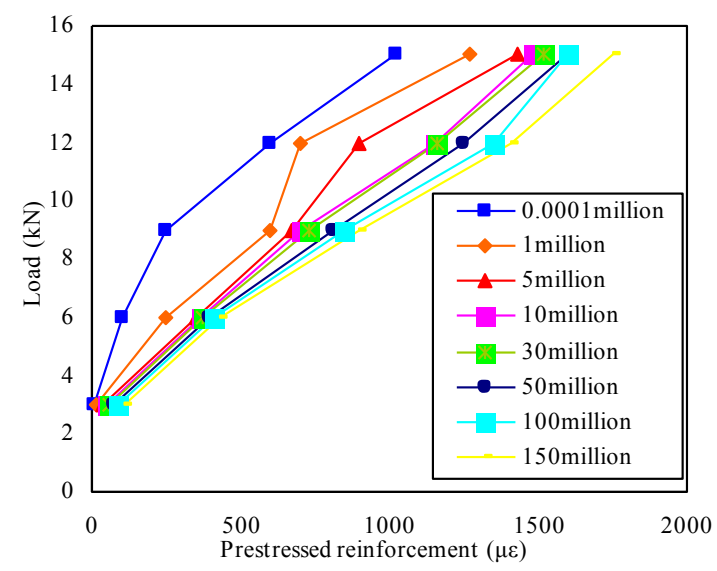

(1)PL4

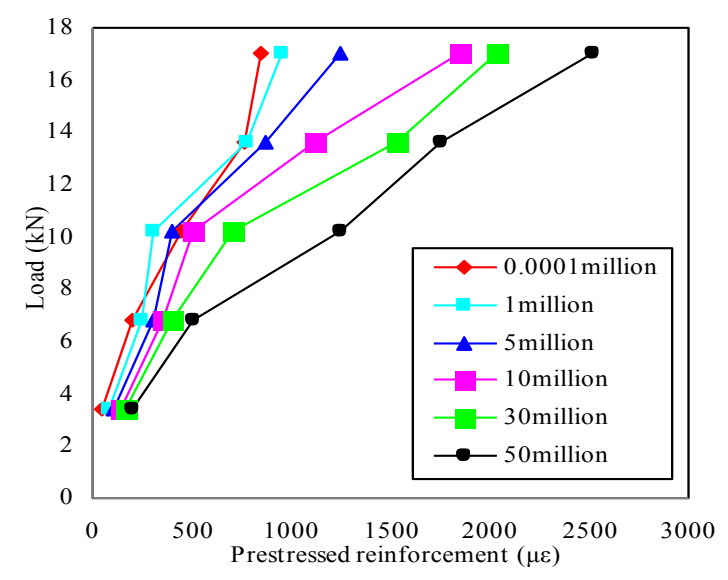

(2)PL5

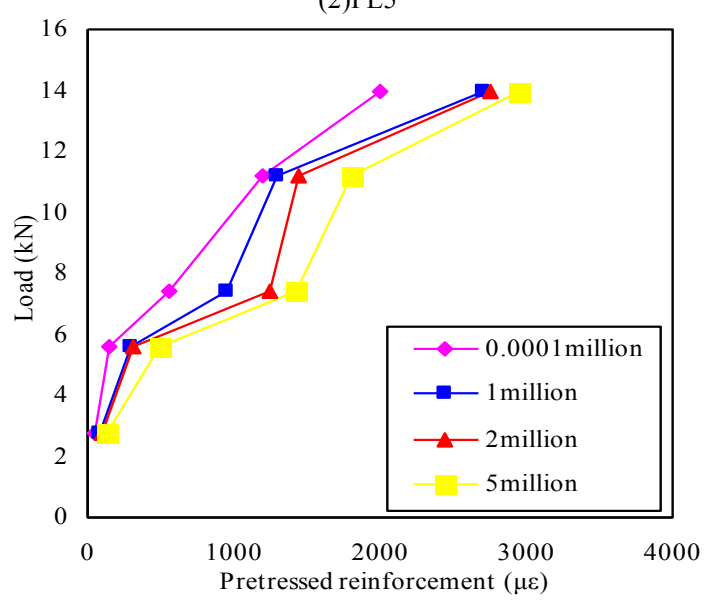

(3)PL6

Fig. 11. Pre-stressed load-strain curve of beams PL4 to PL6 


\section{Conclusions}

The failure modes of pre-stressed concrete beams were described, and the development process of member fatigue failure was analyzed to study the effect of environment corrosion on the fatigue performance of pre-stressed concrete beams. The analysis began with the characteristics of pre-stressed concrete members and was based on indoor corrosion and fatigue tests. The influences of different upper limit load values and corrosion rates on fatigue performance were analyzed based on fatigue failure accumulation theory. The following conclusions were drawn.

(1) Observation of the crack development process and fatigue life of the beams showed that all the test beams suffered bending failure, which began with the brittle rupture of ordinary reinforcement. The fatigue life of the prestressed concrete test beams was restricted by reinforcement corrosion factors. The higher the corrosion rate was, the more marked the brittle failure characteristics of the test beam were. The failure increment continuously increased under the same cycle index of fatigue load during the increase in the cycle index. The time when the test beam underwent plastic deformation was influenced by the corrosion rate (i.e., the higher the corrosion rate was, the earlier the fatigue failure occurred).

(2) Under cyclic fatigue load, the fatigue failure of the concrete of the test beam gradually accumulated, which was manifested by the increase in maximum and residual strains. The maximum strain of the concrete reflected the maximum deformation suffered by the concrete when bearing different loads during the fatigue test. The residual strain of the concrete represented an unrecoverable failure degree and unrecoverable deformation of microcracks generated by the beam after a certain quantity of cyclic loads. The maximum and residual strain curves of the test beams, as well as the rebar strain curve, presented "three-phase" characteristics.
Corrosion rate had a positive correlation with the increment in residual strain.

(3) During the loading process of the fatigue test, the residual strains of concrete in the compressive zone of the two corroded test beams and the number of fatigue tests conformed to the double logarithmic linear relation, with the correlation coefficients being 0.95454 and 0.96361 , respectively.

(4) The yield phase of the pre-stressed reinforcement after corrosion was unobvious. Concrete cracking caused sectional stress redistribution, which then caused plastic deformation of the pre-stressed reinforcement with the accelerated strain increase. The corrosion of the pre-stressed reinforcement could probably result in brittle rupture of the tensile reinforcement.

The analysis results of the fatigue performance of the pre-stressed concrete beams that considered environment corrosion is more consistent with practical engineering than those that did not consider the corrosion influence. This scenario provides a reference basis for safety monitoring, design, and construction in engineering structures. Given that the use environment of bridge structures is complicated and different, single application of the electrochemical corrosion method in this study to simulate the corrosion of bridge structures in practical engineering has certain limitations. Future research should comprehensively consider the different influencing factors of environment corrosion. By doing so, simulations that are in accordance with environmental influencing factors in reality can make the analysis of the corrosive fatigue performance of structures more accurate.

This is an Open Access article distributed under the terms of the Creative Commons Attribution Licence

\section{References}

1. Mehta P.k., "Durability-critical issues for the future". Concrete International, 19(7), 1997, pp.27-33.

2. Liu Chun, Zhu Eryu., "Development of Prestressed Concrete Bridges and Its Durability Research". Railway Engineering, 11, 2005, pp. $1-2$.

3. Zhang W P., Dai H C., Gu X L., "Stochastic model of stress-strain relationship for corroded reinforcing steel bars". Proceedings of the $10^{\text {th }}$ East Asia-Pacific Conference on Structural Engineering and Construction. 2006, pp.457-462.

4. Gao C H., Wang H N., Peng J X., "Bridge engineering development and application of complex corrosive environment simulation system". Highways and Automotive Applications, 1(1), 2012, pp.152-159.

5. Menan F., Henaff G., "Influence of frequency and exposure to a saline solution on the corrosion fatigue crack propagation behavior of the aluminum alloy 2024". International Journal of Fatigue, 31(11), 2009, pp.1684-1695.

6. Wu Q., Yuan Y., "Experimental Study on Degradation Law of Mechanical Properties of Corroded Steel Bar". China Civil Engineering Society, 4 (12), 2008, pp.42-46.

7. Chotickai P., Bowman M D., "Truck models for improved fatigue life predictions of steel bridges". Journal of Bridge Engineering, 11(1),2006, pp.71-80.

8. L. Balsamo., R. Betti., H. Beigi., "A structural health monitoring strategy using cepstral features". Journal of Sound and Vibration, 333(19) 2014, pp. 4526-4542.
9. X.W. Ye., Y.Q. Ni., K.Y. Wong., "Statistical analysis of stress spectra for fatigue life assessment of steel bridges with structural health monitoring data". Engineering Structures, 45, 2012, pp. 166176.

10. Md. S B., Yoshiharu M., Tsutomu M.., "Corrosion fatigue behavior of extruded magnesium alloy AZ61 under three different corrosive environments". International Journal of Fatigue, 30(10), 2008, pp. 1756-1765.

11. Xu H., "Fatigue Strength". Higher Education Press, (8),1988.

12. Ebara R., "Corrosion fatigue crack initiation behavior of stainless steels". Procedia Engineering, 2(1), 2010, pp.1297-1306.

13. Cairns J., Plizzari G.A., Du Y., "Mechanical Properties of Corrosion-Damaged Reinforcement". ACI Mater. J. Technical Paper, 102(4), 2005, pp.256-264.

14. Indrani G., Damodar M., "Influence of sediment layers on dynamic behavior of aged concrete dams". Journal of Engineering Mechanics, 133(4), 2007, pp.400-401.

15. Wang L P., Gong S F., "Study of Electrochemical Corrosion and Bearing Capacity of Corroded Reinforced Concrete Beams". Journal of Shandong University, 39(2), 2009, pp.113-117.

16. Cabrera J G., "Deterioration of concrete due to reinforcement steel corrosion". Cement and Concrete Research, 18(1), 1996, pp.47-59.

17. Yoon S., Wang K., Weiss J., Shah S., "Interaction between loading, corrosion, and serviceability of reinforced concrete". ACI Material Journal, 97(6), 2000, pp.637-644.

18. Ballim Y.,Reid J C., Kemp A R., "Deflection of RC beams under simultaneous load and steel corrosion". Magazine of Concrete Research, 55(4), 2003, pp.405-406. 
19. EI Maaddawy T., Soudki K., Topper T., "Long-term performance of corrosion-damaged reinforced concrete beams". ACI Structural Journal, 102(5), 2005, pp.649-656

20. Yail J. Kim., "Safety assessment of steel-plate girder bridges subjected to military load classification". Engineering Structures, 38, 2012, pp.21-31.

21. Kihyon Kwon, Dan M. Frangopol., "Bridge fatigue reliability assessment using probability density functions of equivalent stress range based on field monitoring data". International Journal of Fatigue, 32(8), 2010, pp.1221-1232.

22. Zhu E Y., Liu C., He L., "Stress Performance Analysis on Corroded Pre-stressed Concrete Beam". China Safety Science Journal, 16(2), 2006, pp.136-140.
23. Pokorný P. , Náhlík L., Hutař P., "Comparison of Different Load Spectra on Residual Fatigue Lifetime of Railway Axle". Procedural Engineering, 74(3), 2014, pp.313-316.

24. Fu G., You J., "Truck Loads and Bridge Capacity Evaluation in China". Journal of Bridge Engineering, 14(5), 2009, pp.327-335.

25. Casas J R., Gómez J D., "Load rating of highway bridges by proofloading”. KSCE Journal of Civil Engineering, 17(3), 2013, pp.556567.

26. Fu G K., Hagelsafi O., "Vehicular overloads,load model, bridge safety, and permit checking". Journal of Bridge Engineering, 5, 2000, pp.49-57.

27. Xin Q., Dou Y M., "Load Spectrum and Fatigue life Computer Aanalysis of Pre-stressed Concrete Bridges". International Journal of Security and Its Applications, 9(7), 2015, pp.247-266. 